\title{
Scientific Profiles in the Field of Female Genital Mutilation/Cutting
}

\section{Mohammad-Hossein Biglu ${ }^{1 *}$, Alireza Farnam ${ }^{2}$ and Parvaneh Abotalebi ${ }^{2}$}

${ }^{1}$ Department of Clinical Psychology, Islamic Azad University, Tabriz, Iran

${ }^{2}$ Research Center of Psychiatry and Behavioral Sciences, Tabriz University of Medical Sciences, Tabriz, Iran

\begin{abstract}
Introduction: Females genital mutilation/Cutting is a harmful traditional procedure disturbing the health of girls and women. It has a continuing sexual, physiological and psychological influence on women health life. The objective of current study was to visualize and analyze the global scientific activities in the field of female genital mutilation/Cutting during a period of 15 years through 2001-2015.

Methodology: A Scientometric analysis was carried out to depict the global activities towards scientific production in the field of female genital mutilation/cutting during a period of 15 years. The Core Collection of Web of Science database was employed to extract all papers indexed as a topic of female genital mutilation/cutting through 2001-2015. The Science of Science Tool was used to map the co-authorship network of papers in the field.

Results: Analysis of data showed that, although the number of papers in the field of female genital mutilation/cutting was not remarkable, but it steady increased through the period of study, so that the number of papers in 2015 was two times greater than those in 2006. English consisting $94 \%$ of total publication was the language of publications. The vast majority of publication type was in the form of journal articles (65\%). Based on the Bradford Scatterings law the journal of "International of Gynecology Obstetrics" was the most productive journal. USA, England and Australia were the most productive countries in the field.

Conclusion: The study concluded that the research activities in the field of FGM/C regarding to the number of circumcised women in the world was very small and insufficient. The psychological aspects of FGM/C have been neglected by the scientists as well as the women health organizations.
\end{abstract}

Keywords: Female genital mutilation; Co-authorship; Web of Science (WOS); Core collection; Scientific analysis

\section{Introduction}

Female Genital Mutilation/Cutting (FGM/C) or women circumcision refers to the procedures of removing total or partial of the external female genitalia or any kind of damaging the female genital organs for non-medical reasons. According to the World Health Organization (WHO) between 100-140 million girls and women have gone under $(\mathrm{FGM} / \mathrm{C})$ and 3 million girls are at risk of circumcision procedures every year [1]. Currently FGM/C procedures are being performed in many countries and regions all over the world, such as Somalia, Egypt, Sierra Leone, Sudan, Mali, Eritrea, and Ethiopia, Iraq, Syria $[2,3]$. Some believes FGM/C is done for securing the virginity of girls or controlling the sexual desires of women [4].

FGM/C is categorized into four types. The most general classification has been defined by WHO as follow:

Type I (“Clitoridectomy”): Removing total or partially the clitoris.

Type II ("Excision"): In addition to the procedure described in type I, parts of the labia minora or the labia minora as a whole are removed. Additional removal of the labia majora may be part of the procedure.

Type III ("Infibulation"): This type consists of the cutting of the labia minora and majora and the joining of the scraped sides of the vulva with or without removal of the clitoris. By sewing the labia together, a vulva covering seal is created.

Type IV: This type includes all other harmful kinds of FGM for non-medical reasons, for example, pricking, piercing, incising, scraping and cauterization of the labia or the vagina [5].

Not only the FGM/C does not have any health benefits for women, moreover it harms the women psychological and physical in many ways. FGM/C has many immediate and/or late complications for women such as pain, haemorrhage, urinary retention, venerable to tetanus, HIV and other psychosomatic complications. The majority of circumcised women have reported mental health problems and emotional disturbances related to the FGM/C. the study of Knipscheer et al. showed that sever level of depression, anxiety and PTSD are highly reported by circumcised women [6].

Considering the prevalence of FGM/C throughout the world reveals clearly the importance of research activities in the field for preventing women against the brutality procedures. It is essential to depict the trend of scientific activities in this subject area for protecting women from psychosomatic complication of FGM/C.

The current study aimed to depict the approach of scientists toward the FGM/C and to answer the following questions:

I. How many scientific papers have been published in the field of FGM/C during 2001-2015?

II. Which institutes or organizations were the most productive in the field?

*Corresponding author: Mohammad-Hossein Biglu, Department of Clinical Psychology, Tabriz Branch, Islamic Azad University, Tabriz, Iran, Tel: +98 4113361300 ; E-mail: Mh_biglu@yahoo.com

Received February 15, 2016; Accepted March 25, 2017; Published April 1 2017

Citation: Biglu MH, Farnam A, Abotalebi P (2017) Scientific Profiles in the Field of Female Genital Mutilation/Cutting. J Health Med Informat 8: 252. doi: 10.4172/21577420.1000252

Copyright: @ 2017 Biglu MH, et al. This is an open-access article distributed under the terms of the Creative Commons Attribution License, which permits unrestricted use, distribution, and reproduction in any medium, provided the original author and source are credited. 


\section{Which countries were productive in the field?}

IV. Which authors played important role in producing and publishing papers in the field?

$\mathrm{V}$. Which authors have had the strategic position in developing the co-authors network of papers in the field of FGM/C?

All papers indexed under the topic of FGM/C in the core collection of Web of Science was extracted and analysed.

\section{Methods}

All papers indexed as a topic of Female genital mutilation or female genital cutting or female circumcision were extracted from core collection of Web of Science during 2001-2015 and analysed.

The core collection of Web of Science (WOS) indexes the bibliographical information of papers from thousands of scholarly journals, books, book-series, reports, conferences, and more. The Web of Science Core Collection provides researchers with access to the world's leading bibliographic and citation databases. Authoritative, multidisciplinary content covers over 12,000 of the highest impact journals worldwide, including Open Access journals, as well as over 150,000 conference proceedings and more than 50,000 editorially selected books.

To retrieve data for the current study, the Web of Science (WOS) Core Collection, our search strategy consisted of the following steps:

- An advanced search was conducted using "female genital mutilation" and alternative search terms, i.e., "female genital cutting", "female circumcision".

- The search was restricted to the occurrence of search terms in the "topic".

- Boolean operator "OR" was applied to the above search terms to produce an exhaustive number of results.

- The search results were filtered to the period of Fifteen years under stud (2001-2015).

- The search results provided 808 records. These numbers of documents were categorized in several sub-categories.

- The data were downloaded in Excel format and analysed.

- The Science of Science Tool was used to map the co-authorship networks of papers in the field of female genital mutilation/ cutting for entire the world. The papers cited more than two times in the WOS Core Collection were considered for mapping the co-authorship network.

Co-authorship is a noticeable and well known practice of scientific collaboration. Almost each feature of scientific collaboration networks can be tracked by considering the co-authorship networks. The scientific co-authorship in scientific community has mainly long history, but analysing the co-authorship networks for exploring the scientific collaboration of scientists is relatively new. Two scientists are considered as co-authors if they have worked together on a paper. Such co-operation between two authors leads to the construction of coauthorship network. Co-authors from different subject area, different institution and different countries may contribute in a specific coauthorship network [7].

The population size for the countries was extracted from the website of World Databank (http://databank.worldbank.org/).

\section{Results}

Extracting of data resulted to 808 research publications which were indexed in the core collection of WOS during years 2001-2015. Analysis of data showed that the number of publication in the field of female genital mutilation/cutting has increased linear through the period of study (Figure 1).

As Figure 1 shows the number of publication has increased through the period of study, in spite of some fluctuation. The number of publication in 2015 was two times greater than those in 200. It reached from 38 papers in 2001 to 105 papers in 2015. The average number of publications was 53 papers annually.

Table 1 shows the origin countries for authors sharing their works

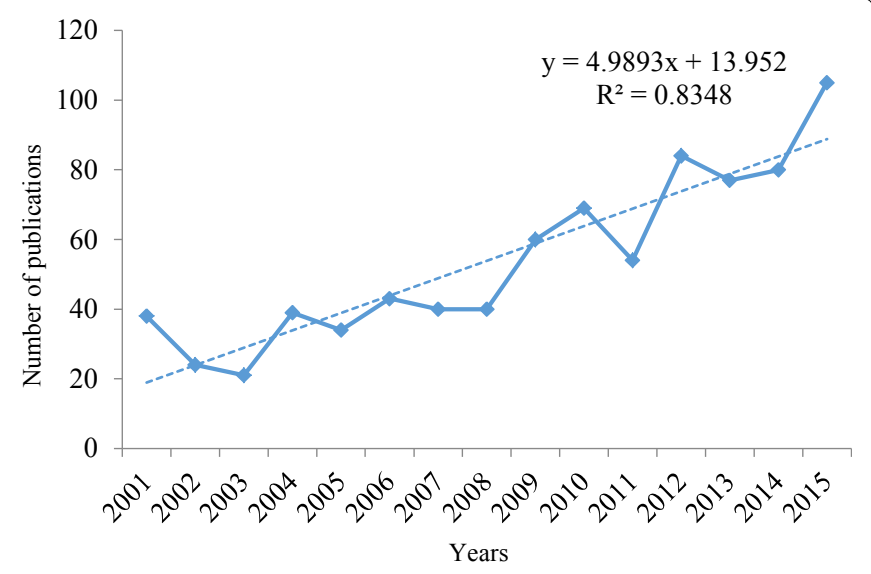

Figure 1: Number of publications in the field of FGM/C in WOS Core Collection 2001-2015.

\begin{tabular}{|c|c|c|c|c|c|c|}
\hline Rank & Countries & $\begin{array}{c}\text { Number } \\
\text { of papers }\end{array}$ & Percent & Population & $\begin{array}{c}\text { Number of } \\
\text { papers/ million } \\
\text { population }\end{array}$ & $\begin{array}{l}\text { Optimized } \\
\text { rank }\end{array}$ \\
\hline 1 & USA & 198 & $24.51 \%$ & $321,418,820$ & 0.62 & 10 \\
\hline 2 & England & 116 & $14.36 \%$ & $63,489,234$ & 1.83 & 5 \\
\hline 3 & Australia & 39 & $4.837 \%$ & $23,781,169$ & 1.64 & 7 \\
\hline 4 & Nigeria & 38 & $4.70 \%$ & $182,201,962$ & 0.21 & 19 \\
\hline 5 & Switzerland & 34 & $4.21 \%$ & $8,286,976$ & 4.10 & 3 \\
\hline 6 & Germany & 34 & $4.21 \%$ & $81,413,145$ & 0.42 & 14 \\
\hline 7 & Egypt & 34 & $4.21 \%$ & $91,508,084$ & 0.37 & 16 \\
\hline 8 & Sweden & 29 & $3.59 \%$ & $9,798,871$ & 2.96 & 4 \\
\hline 9 & France & 28 & $3.47 \%$ & $66,808,385$ & 0.42 & 13 \\
\hline 10 & Canada & 28 & $3.47 \%$ & $35,851,774$ & 0.78 & 9 \\
\hline 11 & Italy & 26 & $3.22 \%$ & $60,802,085$ & 0.43 & 12 \\
\hline 12 & Norway & 22 & $2.72 \%$ & $5,195,921$ & 4.23 & 2 \\
\hline 13 & Spain & 19 & $2.35 \%$ & $46,418,269$ & 0.41 & 15 \\
\hline 14 & Belgium & 19 & $2.35 \%$ & $11,285,721$ & 1.68 & 6 \\
\hline 15 & $\begin{array}{l}\text { South } \\
\text { Africa }\end{array}$ & 16 & $1.98 \%$ & $54,956,920$ & 0.29 & 18 \\
\hline 16 & $\begin{array}{l}\text { Saudi } \\
\text { Arabia }\end{array}$ & 16 & $1.98 \%$ & $31,540,372$ & 0.51 & 11 \\
\hline 17 & Sudan & 13 & $1.61 \%$ & $40,234,882$ & 0.32 & 17 \\
\hline 18 & Netherlands & 13 & $1.61 \%$ & $16,936,520$ & 0.77 & 8 \\
\hline 19 & Slovenia & 12 & $1.49 \%$ & $2,063,768$ & 5.81 & 1 \\
\hline 20 & Ethiopia & 12 & $1.49 \%$ & $99,390,750$ & 0.12 & 20 \\
\hline
\end{tabular}

Table 1: Origin country of papers in FGM/C indexed in WoS Core Collection 2001-2015. 
in the field of female genital mutilation/cutting during the period of study. As shown in the figure the USA sharing $24.51 \%$ of global publication in the field was the most productive country. The following countries were England (14.3\%), Australia (4.8\%), Nigeria (4.7\%) and Switzerland (4.2\%). The last column in in Table 1 provides data based on the number of published papers by each country divided by the number of inhabitants (in millions) of the same country (optimized rank). Measuring the productivity of countries based on the number of papers divided by the size of inhabitants in the same countries, we found that the five top productive countries (after reassessing the respective population size) were Slovenia, Norway, Switzerland, Sweden and England respectively.

Table 2 shows that English was the most dominant language of publications. More than Ninety-four percent of publication was in English; whereas only $6 \%$ of publications were in other languages. This should not come as a surprise while the database of WOS has been focused on papers in English since many years ago [8].

As Figure 2 indicates the vast majority of publication (65\%) was in the form of Journal articles followed by Editorial (9\%) and Review (7\%). Some papers found in the form of Abstracts, meeting, Letter, News and Correlation.

Figure 3 shows the list of journals that distributed the scientific papers in the field of female genital mutilation/cutting through 20012015. The figure is restricted to the journals name that published papers greater than 10 papers in this field. From all of journals that contributed the publications in the field of female genital mutilation/cutting, International of Gynecology Obstetrics publishing 3.71\% (30 papers) of total scientific papers in the field was the most productive journal followed by "Journal of Sexual Medicine" 3.59\% (29 paper), "Lancet" 3.34\% (27 papers), "BMJ British Medical Journal” 3.34\% (27 papers),

\begin{tabular}{|c|c|c|}
\hline Language & Paper & Percent \\
\hline English & 764 & $94.55 \%$ \\
\hline French & 24 & $2.97 \%$ \\
\hline German & 10 & $1.24 \%$ \\
\hline Spanish & 2 & $0.25 \%$ \\
\hline Polish & 2 & $0.25 \%$ \\
\hline Dutch & 2 & $0.25 \%$ \\
\hline Turkish & 1 & $0.12 \%$ \\
\hline Swedish & 1 & $0.12 \%$ \\
\hline Portuguese & 1 & $0.12 \%$ \\
\hline Italian & 1 & $0.12 \%$ \\
\hline
\end{tabular}

Table 2: The language of papers in FGM/C indexed in the WoS Core Collection in years 2001-2015.

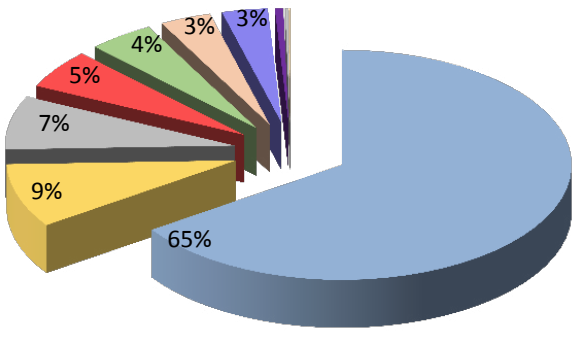

ARTICLE

$\square$ EDITORIAL

REVIEW

- ABSTRACT

MEETING

LETTER

NEWS

- CORRECTION

BIOGRAPHY

Figure 2: Frequency of publication types for papers in the field of FGM/C 2001-2015
"BJOG An International Journal of Obstetrics and Gynaecology" 3.22\% (26 papers), "Reproductive Health Matters" $2.35 \%$ (19 Papers), "British Medical Journal" $1.73 \%$ (14 papers), "Culture Health Sexuality" $1.49 \%$ (12 papers), "Midwifery" 1.49\% (12 papers) and "BMC Public Health" $1.36 \%$ (11 papers).

Table 3 shows the sub-categories of papers in the field of female genital mutilation/cutting. Twenty-three per cent of papers were classified in Obstetrics gynaecology. The following sub-categories were: Public environmental occupational health, General internal medicine, Biomedical social sciences, Nursing, Urology nephrology, Social sciences other topics, Women s studies and Psychology respectively. Table 3 is restricted to 20 top sub-categories.

The productive authors, who shared their works in the field of female genital mutilation/cutting were Abdulrahim A Rouzi from King Abdulaziz University in Saudi Arabia contributing a total number of 12 papers, followed by Matjaz Kuntner from the Slovenian Academy of Sciences and Arts in Slovenia sharing 10 papers; Jasmine Abdulcadir from University Hospitals of Geneva in Switzerland sharing 10 papers; Nawal M. Nour from African Women's Health Center in USA sharing 9 papers. The list of ten top productive authors is shown in Figure 4.

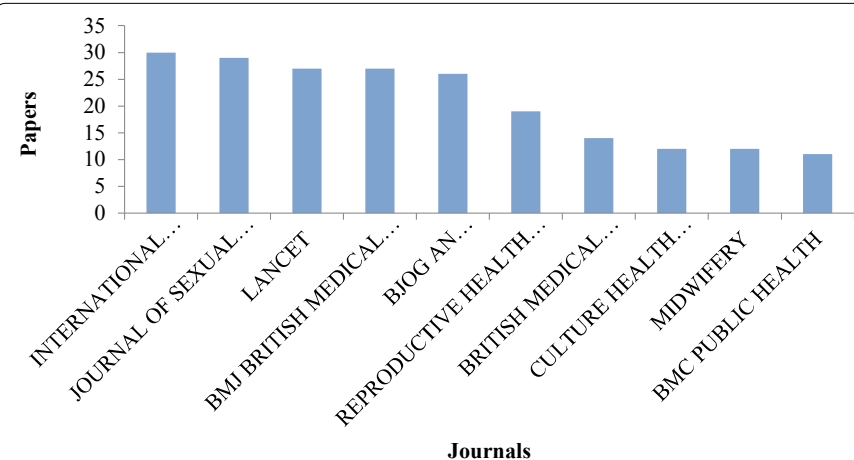

Figure 3: Frequency of journals published scientific papers in the field of FGM/C 2001-2015.

\begin{tabular}{|c|c|c|}
\hline WoS Core Collection categories & Records & Percent \\
\hline Obstetrics gynecology & 193 & $23.89 \%$ \\
\hline Public environmental occupational health & 151 & $18.69 \%$ \\
\hline General internal medicine & 105 & $13.00 \%$ \\
\hline Biomedical social sciences & 61 & $7.55 \%$ \\
\hline Nursing & 42 & $5.20 \%$ \\
\hline Urology nephrology & 39 & $4.83 \%$ \\
\hline Social sciences other topics & 38 & $4.70 \%$ \\
\hline Women s studies & 37 & $4.58 \%$ \\
\hline Psychology & 32 & $3.96 \%$ \\
\hline Reproductive biology & 27 & $3.34 \%$ \\
\hline Family studies & 25 & $3.09 \%$ \\
\hline Pediatrics & 24 & $2.97 \%$ \\
\hline Medical ethics & 24 & $2.97 \%$ \\
\hline Anthropology & 24 & $2.97 \%$ \\
\hline Social issues & 21 & $2.60 \%$ \\
\hline Government law & 21 & $2.60 \%$ \\
\hline Demography & 19 & $2.35 \%$ \\
\hline Tropical medicine & 18 & $2.23 \%$ \\
\hline Immunology & 17 & $2.10 \%$ \\
\hline Sociology & 16 & $1.98 \%$ \\
\hline
\end{tabular}

Table 3: The twenty top sub-categories of FGM/C in the WoS Core Collection in years 2001-2015. 
Figure 5 shows the co-authorship network of papers in female genital mutilation/cutting indexed in the WOS Core Collection 2006-2015. Each circle in the map is the reprehensive of an author, as shown in the map the authors in the field of FGM/C haven't had close cooperation globally, in other words they have worked in small communities.

Figure 5 shows the co-authorship network of papers in the field of female genital mutilation/cutting indexed in the WOS Core Collection 2006-2015. Each circle in the map is the reprehensive of an author, as shown in the map the authors in the field of FGM/C haven't had close cooperation globally, in other words they have worked in small groups.

The largest component of the co-authorship network in the field is shown in Figure 6. We restricted the map into the largest component of the co-authorship network (all small sub-networks have been removed). The map is restricted into authors who had at least two times co-authorship in the field of FGM/C.

Each node is showing an author and every line connecting two authors shows the co-authorship between the authors. Although, the component is not remarkable, but it can illustrate the strategic positions of some authors. Without the works of these authors, the co-authorship network would be divided into some sub-networks. The strategic authors in the co-authorship network are called cut-points and the links between them is called bridges $[9,10]$.

Three authors in the co-authorship network had strategic positions,

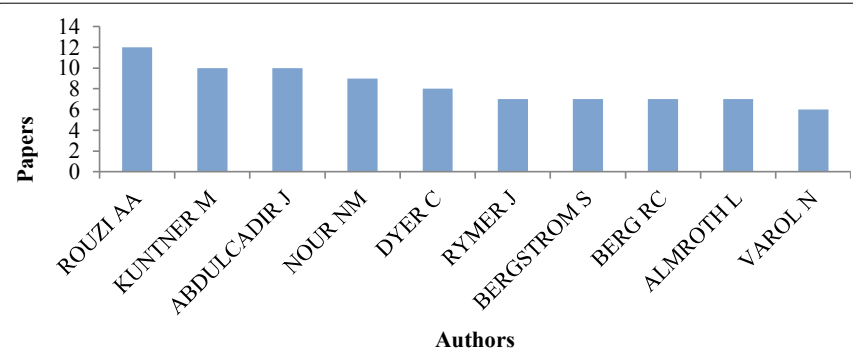

Figure 4: Ten top productive authors in the field of FGM in the WoS Core Collection in years 2001-2015.

Figure 5: The co-authorship network of papers in the field of FGM/C in WOS Core Collection 2001-2015.

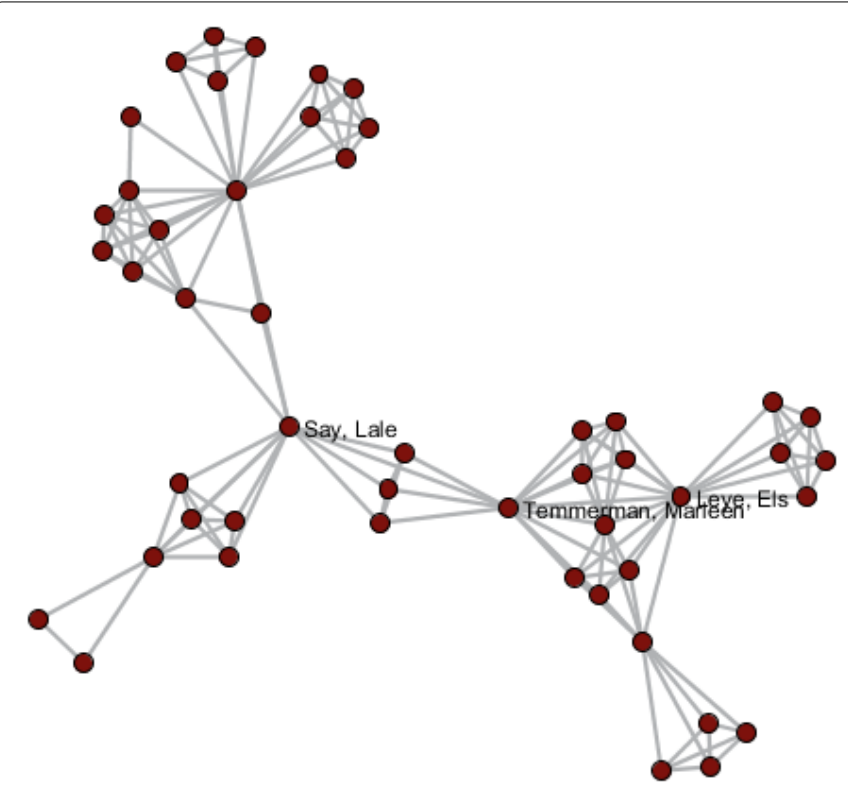

Figure 6: The big component of co-authorship of network in FGM/C in WOS Core Collection 2001-2015.

although these authors did not locate among productive authors, but their position in the network mad them to be as strategic authors. These authors are:

1. Say Laleh sharing 5 papers in the field, from WHO, Dept Reprod Hlth \& Res, CH-1211 Geneva, Switzerland.

2. Temmerman marleen (sharing 3 papers) from WHO, Dept Reprod Hlth \& Res, Geneva, Switzerland.

3. Leye Els (sharing 4 papers) from Univ Ghent, ICRH, B-9000 Ghent, Belgium.

\section{Discussion}

The main aim of current study was to analyse the papers in the field of female genital mutilation/cutting indexed in the core collection of WOS for a period of 15 years, and to map the co-authorship network of scientific output in the field.

The study showed that during the period of study, a total number of 808 papers in the field of female genital mutilation/cutting were published in the journals that indexed in the WOS Core Collection. Although the number of publication through the time span was not remarkable, but the number of publication showed relatively illustrious increase during the period of study. Considering the existence evidences that estimate more 200 million women from more than 28 countries in the world which have gone under circumcision procedures, the number of publication related to the FGM/C is very small and insufficient.

Although over the years, a strong trend representing the increased tendency of published papers focusing on the problematic consequences of FGM/C can be seen. This should not come as a surprise, since the rise of global attention on this issue has increased over the last by the $\mathrm{UN}$ [11], as well as numerous reports and declarations by international agencies contributed to abandon the FGM/C [12]. The study conducted by Sweile [13] emphasized that measuring the research activity about the impact of publications in FGM/C can considered as a new calculation in the literature of FGM/C. Her study revealed that the literature of science in the field of FGM/C was growing and distributing in the high 
impacts journals. In addition, numerous countries are collaborating in creating the scientific literature of science in FGM/C. this is a hint that FGM/C has become an interesting issue among scientist all over the word and the results of such activities definitely would reveal the negative consequences of $\mathrm{FGM} / \mathrm{C}$ on psychosomatic situation of women in the world and scientometric analysis would be the main step of tracking the growth of FGM/C research and literature.

When we are considering the subcategories of published papers in FGM/C, we find out that the number of papers in the sub-category of psychology is very small. However, we are aware that FGM/C makes many psychosomatic complications for circumcised women.

Considering the side effects of FGM/C especial the psychological conditions such as PTSD, anxiety, stress, post trauma depression, panic disorder, social phobia and many other problems, we find out that investigation about the influence of FGM/C on the health of women is important and crucial. The study conducted by Eisold showed that FGM/C cans effects on emotional well-being of women throughout their life [14].

The study of Pechmann et al. showed that the FGM/C is associated many psychological disorders as anxiety, depression, and posttraumatic stress disorder [15]. Other study conducted by Knipscheer et al. indicated that FGM/C had relationship with anxiety disorders, posttraumatic stress disorder and other psychopathology problems [6].

The results of the current study definitely indicate that the psychological aspects of FGM/C have been neglected through the last fifteen years. This is an indication that the scientists and the policy makers of women health organizations should lead the future researches and resources towards the psychological aspects of FGM/C for helping such women in the world.

Although the majority of publications in the subject area of FGM/C in the WOS Core Collection database were from the USA, but when the productivity of countries is considered regarding to the size of countries inhabitants, it reveals that Slovenia, Norway, Switzerland, Sweden and England are the five top productive countries. Nevertheless, this study is not the first to show the dominance of these countries in producing and publishing scientific profiles, other studies have also confirmed the productivity of these countries [16-18].

English was the leading language of papers which is not unusual; since the editorial policy of this database focuses on selecting papers written in English since many years ago [17].

\section{Conclusion}

The study concluded that the research activities in the field of FGM/C compared to the number of circumcised women in the world is very small and insufficient. The psychological aspects of FGM/C have been neglected by the scientists as well as the women health organizations.

The co-authorship network indicated that the researchers in the field have worked in small communities so that the density of network is very small. The co-author network strongly indicated that the scientists need to join the international research teams.

\section{References}

1. Ohchr U, Undp U, Unesco U, Unhcr U, Unifem W (2008) Eliminating female genital mutilation: An interagency statement. Geneva: WHO.

2. Berg RC, Denison E (2013) A tradition in transition: factors perpetuating and hindering the continuance of female genital mutilation/cutting (FGM/C) summarized in a systematic review. Health Care for Women International 34 837-859

3. United Nations Children's Fund (UNICEF) (2013) Female Genital Mutilation/ Cutting: A statistical overview and exploration of the dynamics of change. New York: Unicef 21: 184-190.

4. World Health Organization (WHO) (1999) Female genital mutilation: Information kit.

5. World Health Organization WHO (2011) An update on WHO work on female genital mutilation (FGM): Progress Report.

6. Knipscheer J, Vloeberghs E, Kwaak AVD, Muijsenbergh MVD (2015) Menta health problems associated with female genital mutilation. BJ Psych Bull 39 273-277.

7. http://www.unfpa.org/resources/female-genital-mutilation-fgm-frequently asked-questionshttp://www.unfpa.org/resources/female-genital-mutilationfgm-frequently-asked-questions

8. Biglu S, Biglu MH, Falk C (2011) P01-511-Scientometric study of scientific production in psyciatry. Eur Psychiatry 26: 515.

9. Biglu MH, Biglu S (2014) Scientific attitudes towards bipolar disorders. J Analyt Res Clin Med 2: 1-10.

10. Biglu MH, Ghavami M, Biglu S (2014) Authorship, institutional and citation metrics for publications on postmenopausal osteoporosis. Osteoporos Int 25 $1337-1343$.

11. http://www.un.org/en/events/femalegenitalmutilationday/http://www.un.org/en/ events/femalegenitalmutilationday/

12. Unicef (2016) Female genital mutilation/cutting: a global concern. New York: Unicef 1: 1-2.

13. Sweileh WM (2016) Bibliometric analysis of literature on female genital mutilation (1930-2015). Reproduct healt 13: 130

14. Eisold BK (2015) Female Genital Mutilation and its Aftermath in a Woman who Wished to "Have a Life:" Submission as a Route to the Preservation of Personal Agency. Int J Appl Psychol Stud 13: 279-304.

15. Pechmann C, Petermann F, Schmidt S, Nitkowski D, Koebach A, et al. (2016) Coping Process in Women with FGM from Ethiopia-The Contribution of Attitude. Psychotherapie, Psychosomatik, medizinische Psychologie 66: 421

16. Biglu $\mathrm{MH}$, Asgharzadeh A (2011) The prevalence of stress factor among medicine students in Iran. Europ Psych 26: 1577.

17. Biglu MH, Riazi S (2015) Network of nanomedicine researches: impact of iranian scientists. Biolmpacts: BI 5: 199.

18. Glynn RW, Scutaru C, Kerin MJ, Sweeney KJ (2010) Breast cancer research output, 1945-2008: a bibliometric and density-equalizing analysis. Breast Cancer Res 12: 1 